\title{
TENSILE TESTS OF NIOBIUM MATERIAL FOR SRF CAVITIES
}

\author{
G. Wu ${ }^{1}$, N. Dhanaraj ${ }^{1}$, L. Cooley ${ }^{1}$, D. Hicks ${ }^{1}$, E. Hahn ${ }^{1}$, D. Burk ${ }^{1}$, \\ W. Muranyi ${ }^{1}$, M. Foley ${ }^{1}$, H. Edwards ${ }^{1}$, E. Harms ${ }^{1}$, M. Champion ${ }^{1}$, D. \\ Baars $^{2}$, and C. Compton ${ }^{2}$ \\ ${ }^{1}$ Fermi National Accelerator Laboratory \\ Batavia, Illinois, 60510, U.S.A. \\ ${ }^{2}$ Michigan State University \\ East Lansing, Michigan, 48824, U.S.A.
}

\begin{abstract}
Mechanical tests of cavity-grade niobium samples were conducted to provide engineering information for the certification of 3rd-harmonic superconducting radio-frequency cavities and cryomodules. Large changes of mechanical properties occur throughout the cavity fabrication process due to the cold work introduced by forming, the heating introduced by electron beam welding, and the recovery of cold work during the anneal used to degas hydrogen after chemical processing. Data is provided here to show the different properties at various stages of fabrication, including both weld regions and samples from the bulk niobium far away from the weld. Measurements of RRR were used to assure that any contamination during annealing was negligible.
\end{abstract}

KEYWORDS: superconducting radio-frequency cavity, niobium, mechanical testing, niobium mechanical properties, residual resistivity ratio.

\section{INTRODUCTION}

Superconducting radio-frequency (SRF) cavities are an enabling technology for highenergy physics and nuclear physics machines that probe frontiers of energy, power, and beam intensity. Over the past $\sim 2$ decades of research, specifications for niobium sheets [1,2], from which SRF cavities are formed, have been developed to ensure that high purity and good formability are simultaneously achieved. These specifications apply controls to interstitial gas and impurity atom contents (through the residual resistivity ratio RRR), 
hardness, yield stress, elongation to failure, strain coefficient, grain size, and sheet flatness. Extensive quality control has also been implemented at the major SRF laboratories, including mechanical tests, eddy-current scans, and other materials science. One benefit of the standard specifications has been the reduction of the range of properties in starting sheet stock, which depends on the forming and annealing history. Nonetheless, mechanical testing is vital for obtaining the actual engineering properties.

In this paper, we report niobium testing to provide data for engineering notes to accompany $3.9 \mathrm{GHz}$ cryomodule built by Fermilab for delivery to DESY [3]. Material was fabricated and tested at Fermilab, with additional tests being performed at Michigan State University. In addition to the as-received sheets, which are annealed and recrystallized, tests included samples taken after forming a sheet into a seamed tube to simulate the cold work given to half cells. The seam provided samples of electron-beam welds. Also, samples were baked under conditions used to de-gas hydrogen from chemical processing, i.e. at $800{ }^{\circ} \mathrm{C}$ in a high-vacuum oven for 2 hours. The baking step is critical, because it occurs at the end of cavity processing and therefore provides the final mechanical state of the cavity. The results reported here show good uniformity between different samples at the same stage of fabrication, as well as good agreement between tests conducted at both laboratories.

\section{EXPERIMENT}

\section{Preparation of Tensile Test and Residual Resistivity Ratio Samples}

The test specimens were obtained from a $178 \mathrm{~mm}$ long seamed niobium tube used to qualify electron beam welding for the manufacture of $3.9 \mathrm{GHz} \mathrm{SRF}$ cavities. The tube forming was thought to be a good approximation to the cold work given to half cells. The tube was made from a niobium sheet by rolling to a $45.6 \mathrm{~mm}$ outer diameter and joining with a full-penetration electron beam weld along the longitudinal seam. The weld power was adjusted appropriately for the $2.5 \mathrm{~mm}$ niobium thickness, which is thicker than the 2.2 mm thickness used for a typical $3.9 \mathrm{GHz}$ cavity equator weld. Six samples were cut along the tube axis using wire electrical discharge machining (EDM). Of these samples, four nominally $6 \mathrm{~mm}$ wide by $100 \mathrm{~mm}$ long samples were from non-welded regions of the tube, and two nominally $7 \mathrm{~mm}$ wide by $88 \mathrm{~mm}$ long samples were cut from welded regions. The actual dimensions and sample identifiers are reported in TABLE 1.

Dog-bone samples were then machined according to ASTM E8 specifications [4]. For non-welded samples 1-4, the specimens' widths were reduced by $0.5 \mathrm{~mm}$ on each side for the central $50 \mathrm{~mm}$ length. Weld samples 5 and 6 were thinned by $1.0 \mathrm{~mm}$ over the central $38 \mathrm{~mm}$ (thus the gauge width was close to that for the non-welded samples). A $6 \mathrm{~mm}$ radius was used to round the transitions in width. A small hole of $0.6 \mathrm{~mm}$ diameter was drilled $2 \mathrm{~mm}$ from one end of each sample to facilitate hanging the sample by a fine niobium wire in the vacuum oven for annealing.

Fermilab conducted tensile tests on samples 1, 2, 4, 5 and 6, and Michigan State tested sample 3. Tests at Fermilab were carried out using Instron model 4411. The tensile test at Michigan State University was carried out using 4200 series Instron Model 43K2. Both models used the same strain rate of $1.25 \mathrm{~cm}$ per minute.

In addition to samples for tensile testing, bars nominally $75 \mathrm{~mm}$ long by $4.8 \mathrm{~mm}$ wide by $2.0 \mathrm{~mm}$ thick were cut by EDM for measurement of the residual resistivity ratio (RRR). As with the tensile test specimens, a $0.6 \mathrm{~mm}$ diameter hole was drilled $2.0 \mathrm{~mm}$ from one 
TABLE 1. Dimensions of the test specimens.

\begin{tabular}{|c|c|c|c|c|c|}
\hline \multicolumn{2}{|c|}{ Required Dimensions (mm) } & \multicolumn{4}{|c|}{ Measured Dimensions (mm) } \\
\hline \multicolumn{6}{|c|}{ Tensile samples from non-welded region } \\
\hline & & sample \#1 & sample \#2 & sample \#3 & sample \#4 \\
\hline Overall length & 101.6 & 101.9 & 101.9 & 101.9 & 101.9 \\
\hline Width at grip section & $6.35 \pm 0.25$ & 6.35 & 6.35 & 6.35 & 6.35 \\
\hline Width at gage section & 5.33 & 5.33 & 5.33 & 5.33 & 5.33 \\
\hline Thickness & $2.54 \pm 0.25$ & 2.59 & 2.59 & 2.59 & 2.59 \\
\hline $\begin{array}{l}\text { Hole location from } \\
\text { end }\end{array}$ & 2.00 & 1.94 & 1.88 & 2.11 & 2.16 \\
\hline Grip length & 25.4 & 25.4 & 25.6 & 25.8 & 25.7 \\
\hline \multicolumn{6}{|c|}{ Tensile samples from welded region } \\
\hline & & sample \#5 & sample \#6 & & \\
\hline Overall length & 88.9 & 88.3 & 88.3 & & \\
\hline Width at grip section & $7.11 \pm 0.25$ & 7.11 & 7.11 & & \\
\hline Width at gage section & 5.33 & 5.33 & 5.33 & & \\
\hline Thickness & $2.54 \pm 0.25$ & 2.49 & 2.48 & & \\
\hline $\begin{array}{l}\text { Hole location from } \\
\text { end }\end{array}$ & 2.00 & 1.98 & 2.08 & & \\
\hline $\begin{array}{l}\text { Grip length at jagged } \\
\text { end }\end{array}$ & 25.4 & 25.0 & 25.0 & & \\
\hline $\begin{array}{l}\text { Grip length at other } \\
\text { end }\end{array}$ & 25.4 & 25.7 & 25.6 & & \\
\hline \multicolumn{6}{|c|}{ RRR samples from non-welded region } \\
\hline & & RRR sample \#7 & RRR sa & & \\
\hline Overall length & 76.2 & 75.4 & 75.2 & & \\
\hline Width & $4.83 \pm 0.13$ & 4.83 & 4.83 & & \\
\hline Thickness & $2.03 \pm 0.13$ & 2.06 & 2.07 & & \\
\hline Hole loc. from end & 2.0 & 2.1 & 2.2 & & \\
\hline
\end{tabular}

end of each RRR sample. These samples serve as witness samples to evaluate possible contamination during annealing. The actual sample dimensions are also given in TABLE 1 .

\section{Annealing and Etching}

Sample 3, 4, 6 and 8 were etched in a buffered chemical polishing solution (1 part nitric acid, 1 part hydrofluoric acid, and 2 parts phosphoric acid by volume) for 15 minutes at $12-15{ }^{\circ} \mathrm{C}$ to remove surface imperfections. This was followed by rinsing in deionized water, drying, and baking in ultra-high vacuum at $800{ }^{\circ} \mathrm{C}$ for 2 hours. A residual gas analyzer attached to the furnace monitored outgassing and decomposition of surface oxides. This equipment also indicated that the duration of the heat treatment was long enough to remove most hydrogen from the etching step.

\section{RRR measurements}

The value of RRR was determined by comparing the sample resistance at $293 \mathrm{~K}$ to that at $\sim 10 \mathrm{~K}$, i.e. just above the resistive superconducting transition in zero applied field. The RRR definition adopted here is simpler than RRR standards that use the ice point as a reference, with differences of about $10 \%$ [5].

\section{Results and Discussion}

Stress-strain curves are plotted in FIGURE 1. In addition, reference data to another weld sample, called "2006 sample", was also plotted to compare the weld orientation 


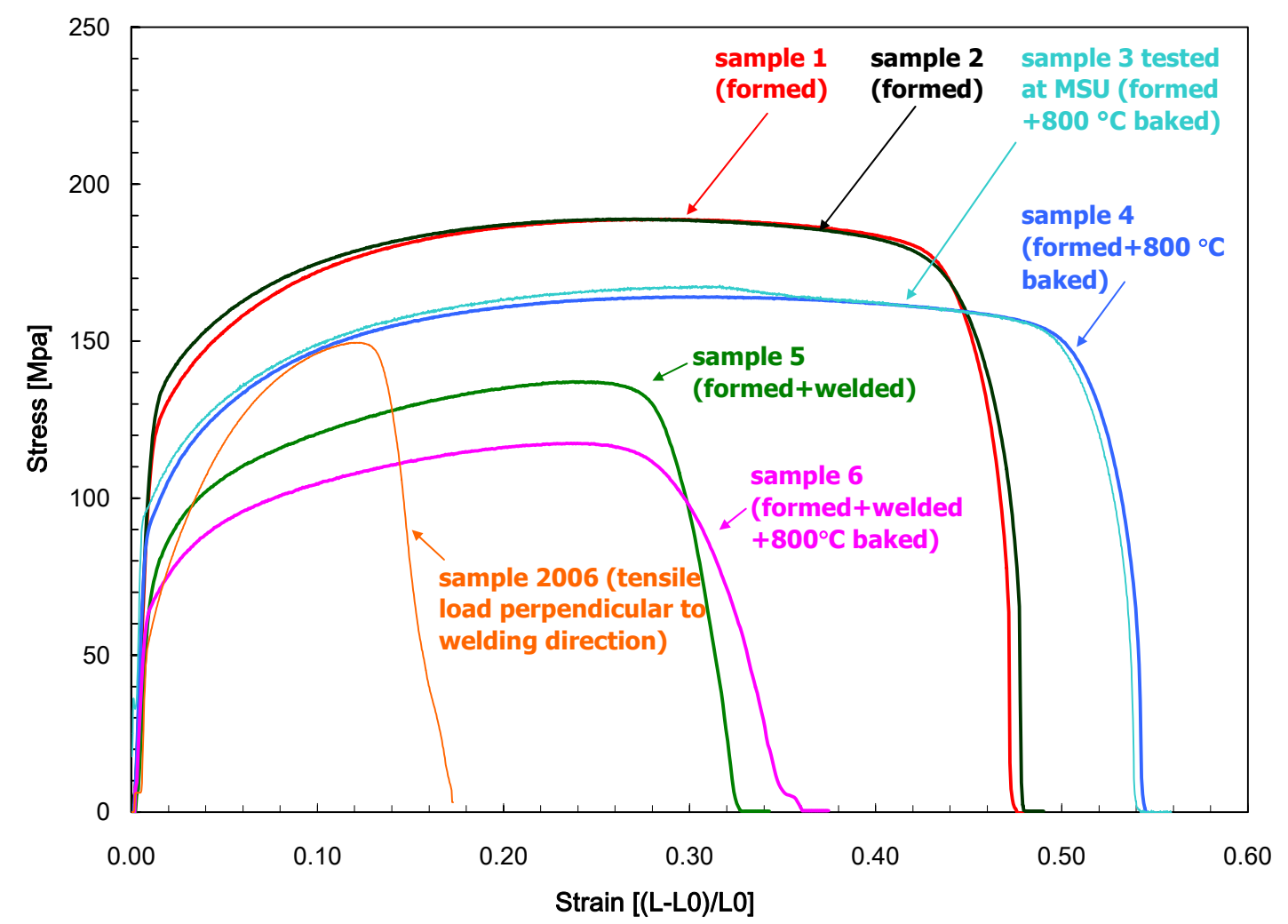

FIGURE 1. Stress strain curves for samples 1-6. A 2006 sample (described in the text) is also shown for comparison.

effect. The 2006 sample shows the strongly different behavior when the force is applied transverse to the weld. The tensile test break point shown in FIGURE 2 corresponded to tensile failures within the gauge length section. Yield strength and ultimate tensile stress are listed in TABLE 2. Preload offsets were compensated through both software and manual adjustments to the load cell. The stress-strain curves show good agreement between the tests for the sample pairs (samples 1 and 2, and the inter-laboratory comparison samples 3 and 4). Significant reduction of the yield stress, and increase in the elongation to failure, are observed for the annealed samples as expected.

The weld samples showed significant reduction of ductility compared to the other samples. This is due to the large grains in the weld, which comprise a significant fraction of the sample cross-section. A photograph of the annealed tensile specimens is shown in FIGURE 3 .

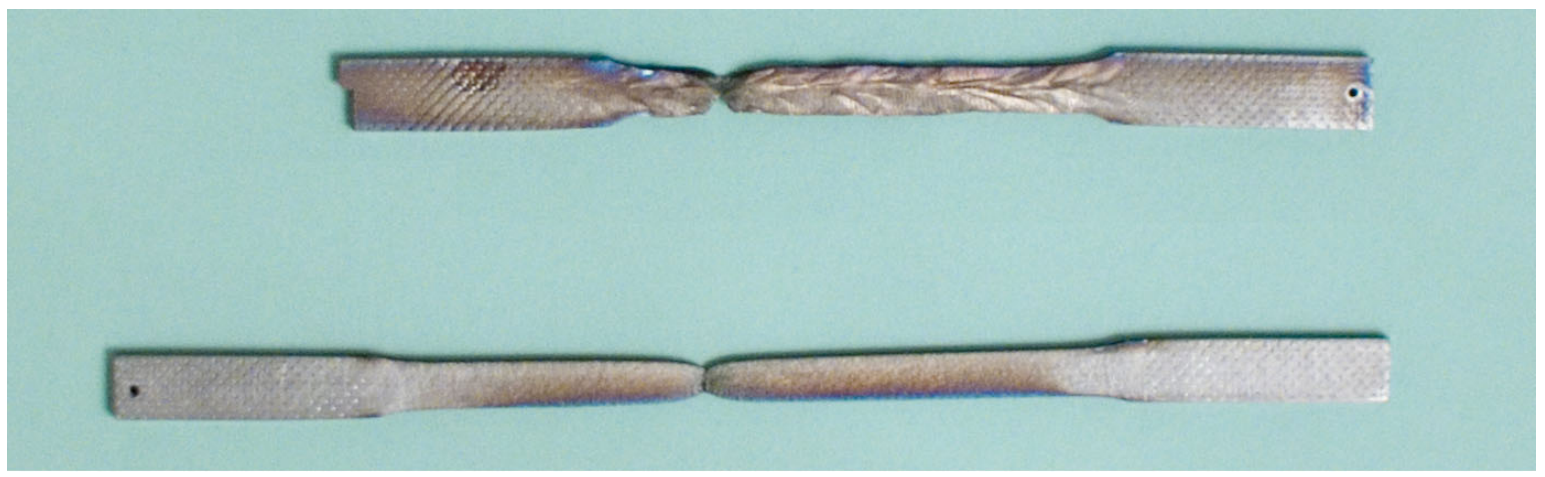

FIGURE 2. Tensile samples 6 (top) and 4 (bottom) after the tensile test. 
RRR measurements show some degradation of sample purity during forming, which is to be expected due to the buildup of dislocations. Annealing largely restores the RRR value (see sample 4) to the values reported from vendor data. Some degradation of the RRR is found for the weld samples, indicating some contamination occurred. This contamination may be on the sample surface, since annealing further degrades the RRR value as might be expected if surface contamination were more deeply distributed through the bulk.

\section{DISCUSSION AND CONCLUSIONS}

Niobium mechanical properties have been reported earlier [6-8] and showed wide variations depending on material stock history, purity, and microstructure. They also evolve during manufacturing processes, as also reported here. The tensile test data reported in this paper falls between the mechanical properties reported elsewhere. Importantly, the information here attempts to track the changes in mechanical properties step by step through the fabrication and etching process.

This result provided necessary assurance for engineering analysis and documentation for the Fermilab 3.9 GHz cryomodule [9]. The application of niobium cavities together with vacuum and pressurized helium constitutes a pressure vessel condition, since the diameter of the dressed cavity is larger than $15 \mathrm{~cm}$ and therefore it falls within the definition of U.S. pressure vessel codes. The engineering data here provided key data for certification and delivery of these cavities to DESY.

TABLE 2. Mechanical properties and RRR results. Vendor data refers to data supplied with the material batch, with different samples taken transverse to (Trans.) or along (Long.) the sheet rolling direction.

\begin{tabular}{|c|c|c|c|c|}
\hline Samples & $\begin{array}{c}\text { Yield } \\
\text { Strength }^{\mathrm{a}} \\
(\mathrm{MPa})\end{array}$ & $\begin{array}{c}\text { Tensile } \\
\text { Strength } \\
(\mathrm{MPa})\end{array}$ & RRR & Grain size $(\mu \mathrm{m})$ \\
\hline Vendor data 1 (Trans.) & 54.5 & 166.9 & 418 & $40-50($ ASTM 6) \\
\hline Vendor data 1 (Long.) & 62.1 & 167.5 & 423 & ASTM 6 \\
\hline Vendor data 2 (Trans.) & 61.4 & 164.1 & 458 & ASTM 6 \\
\hline Vendor data 2 (Long.) & 78.6 & 165.5 & 449 & ASTM 6 \\
\hline 1 Formed & 117.0 & 189.0 & 306 & 80 \\
\hline 2 Formed & 120.0 & 188.7 & & \\
\hline 3 Formed $+800{ }^{\circ} \mathrm{C} 2 \mathrm{~h}$ & 95.6 & 167.1 & & \\
\hline 4 Formed $+800^{\circ} \mathrm{C} 2 \mathrm{~h}$ & 91.0 & 164.0 & 410 & 80 \\
\hline 5 Formed + Weld & 71.0 & 137.1 & 384 & 1100 \\
\hline 6 Formed + Weld $+800^{\circ} \mathrm{C} 2 \mathrm{~h}$ & 64.0 & 117.1 & 347 & 1000 \\
\hline Sample 2006 center weld & 57.1 & 149.6 & & \\
\hline
\end{tabular}

\footnotetext{
${ }^{\mathrm{a}}$ Yield strength at $0.2 \%$ offset.
} 


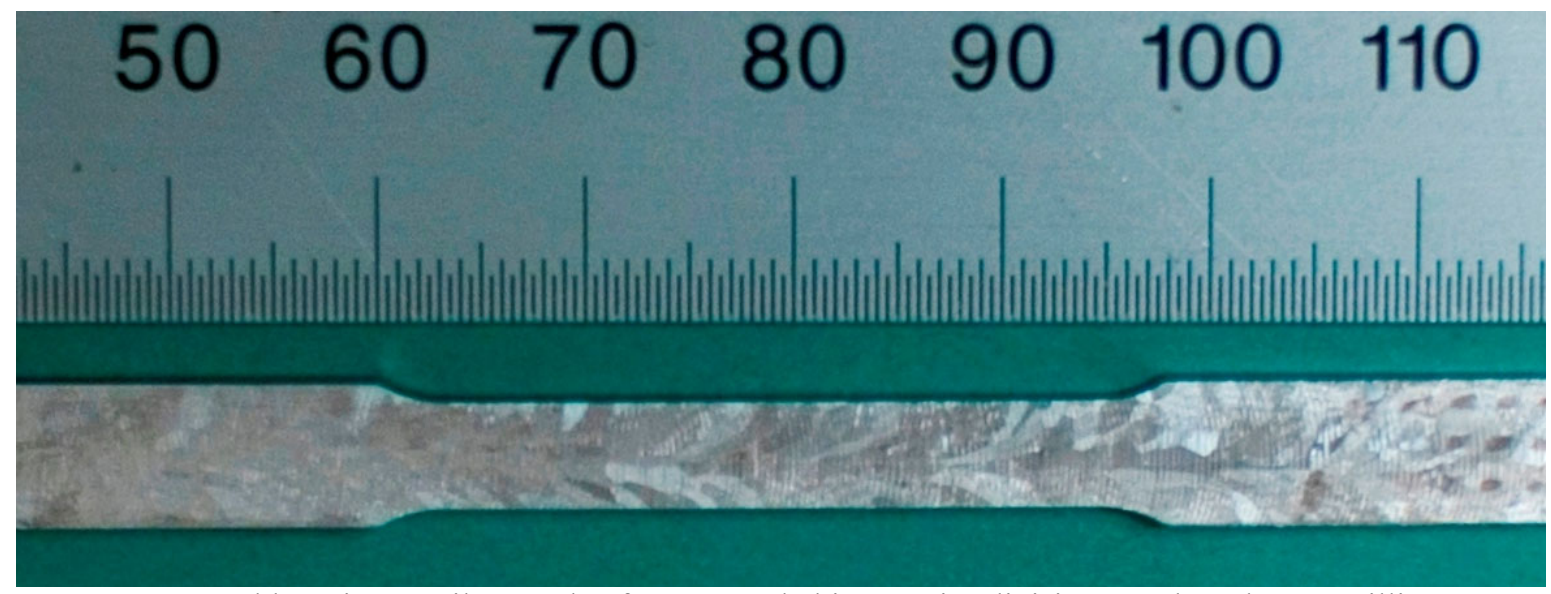

FIGURE 3. Weld section tensile sample after $800{ }^{\circ} \mathrm{C}$ baking. Major divisions on the ruler are millimeters.

\section{ACKNOWLEDGMENTS}

The work is supported by U.S. Department of Energy under contract \# DE-AC02$07 \mathrm{CH} 11359$.

\section{REFERENCES}

1. Cooley, L.D., Fermilab Niobium Material Specification 5500-ES-371037 Rev A, 2008.

2. Singer, W., Proch, D., "Technical Specification for Niobium Applied for the Fabrication of $1.3 \mathrm{GHz}$ Superconducting Cavities, RRR 300," DESY Lab-Note 1/96, Version E, January, 2002.

3. Edwards, H.T., Arkan, T.T., Foley, M.H., Ge, M., Harms, E.R., Hocker, A., Khabiboulline, T.N., McGee, M.W., Mitchell, D.V., Olis, D.R., Rowe, A.M., Solyak, N., "Construction of a 3.9 GHz Superconducting RF Cavity Module at Fermilab," Proc. of Particle Accelerator Conference, Vancouver, Canada, 2009.

4. ASTM Standard E8/E8m, 2008, "Standard Test Methods for Tension Testing of Metallic Materials," ASTM International, West Conshohocken, PA, 2008, DOI: 10.1520/E0008_E0008M-08, www.astm.org.

5. Bauer, P., Berenc, T., Boffo, C., Foley, M.H., Kuchnir, M., Tereshkin, Y., Wokas, T., "RRR Measurements on Niobium for Superconducting RF Cavities at Fermilab," Proc. of 11th International Workshop on RF Superconductivity, Lubeck, Germany, 2003.

6. Myneni, G.R., Kneisel, P., "Thermal and Mechanical Properties of Electron Beam Welded and HeatTreated Niobium for Tesla," Proc. of. 6th International Workshop on RF Superconductivity, CEBAF, Newport News, VA, 1993, pp. 643-649.

7. Myneni, G.R., Kneisel, P., "Mechanical Properties of High RRR Niobium at Cryo-temperature," Advances in Cryogenic Engineering, Vol40, edited by R. P. Reed, F. R. Fickett, L. T. Summers, M. Stieg, Plenum Press, New York, 1994, pp. 1383-1390.

8. Walsh, R.P., Mitchell, R.R., Toplosky, V.T. and Gentzlinger, R.C., "Low Temperature Tensile and Fracture Toughness Properties of SCRF Cavity Structural Materials," Proc. of. 9th International Workshop on RF Superconductivity, Sante Fe, New Mexico, 1999, pp. 195-197.

9. Peterson, T.J., Carter, H.F., Foley, M.H., Klebaner, A.L., Nicol, T.H., Page, T.M., Theilacker, J.C., Wands, R.H., Wong-Squires, M.L. and Wu, G., "Pure Niobium as a Pressure Vessel Material," this proceedings. 